\title{
A STELLA-II teaching simulation of the dynamics of action model
}

\author{
VIRGINIA BLANKENSHIP and JUSTIN TUMLINSON \\ Northern Arizona University, Flagstaff, Arizona \\ and \\ MARK A. SIMS \\ Netrex, Inc., Southfield, Michigan
}

\begin{abstract}
Although the Atkinson and Birch (1970) dynamics of action model of behavior is included in many textbooks, the details of the model are left out. To facilitate the teaching of the full theory, the conceptual model is outlined, research findings are reviewed, and a simulation model using STELLA-II is presented. STELLA-II, an icon-based program, provides a visual representation of the model that students can follow, with graphical and tabular output and animation of the rise and fall of parameter values.
\end{abstract}

In 1970, Atkinson and Birch published the dynamics of action theory, a model of behavior and its underlying motivation. The first computer simulation of that theory was written by Seltzer (1973) and Seltzer and Sawusch (1974) in FORTRAN IV-G. In 1975, Bongort completed a version of the dynamics of action written in FORTRAN IV, incorporating OSIRIS subroutines. In 1986, D. J. Atkinson published a version in BASIC. It is the purpose of this article to present a conceptual simulation of the dynamics of action theory done with STELLA-II, a product of High Performance, Inc., a version that can be used for teaching purposes.

\section{THE DYNAMICS OF ACTION THEORY}

In the dynamics of action theory, behavior is conceptualized as a stream; one behavior or activity flows into the next, and the sequence of activities is determined by forces below the surface: instigating forces, inhibitory forces, forces of resistance, and consummatory forces. Each activity is represented by its resultant action tendency ( $T$ or BAR-T), the algebraic combination of the positive action tendency $(T)$ and the negative action tendency or negaction tendency $(\mathrm{N})$ : BAR-T $=\mathrm{T}-\mathrm{N}$. The instigating force $(F)$ causes the action tendency $(T)$ to rise through time. For example, let us imagine a person sitting at a computer and working on an article; to that person's right is a fresh doughnut. The ongoing activity consists of typing on the computer, which, because it has

Work on this project was supported by an Organized Research grant through Northern Arizona University. We wish to thank Anne Bromley, Ann Beck, and Randi Reppen for their editorial assistance. Requests for reprints and for copies of the data files to be used with STELLA-II should be addressed to V. Blankenship, Department of Psychology, Northern Arizona University, Box 15106, Flagstaff, AZ 86011 (e-mail: vrb@nauvax.ucc.nau.edu). STELLA-II may be purchased from High Performance Systems, Inc., 45 Lyme Road, Hanover NH 03755 . stabilized, would be represented by a horizontal line, neither rising nor falling through time (see Figure 1). However, as time passes, the tendency to eat the doughnut increases as a result of the instigating force arising from the immediate stimulus situation (the presence of the doughnut, its proximity to the writer) as well as previous experience with fresh doughnuts. The instigating force is high (the slope of the line is steep) because the doughnut is appealing; the force would be lower (the slope of the line would be flatter) if the doughnut were stale.

But let us also imagine that the person is on a diet and knows that eating the doughnut will reverse previous weight loss. This knowledge creates an inhibitory force (I) that increases a negaction tendency $(N)$ not to eat the doughnut. Again, the resultant action tendency (BAR-T) is equal to the action tendency minus the negaction tendency $(T-N)$. As long as the resultant tendency to eat the doughnut is less than the resultant tendency to type on the computer, the doughnut will remain on its plate. However, a force of resistance (R) is working to reduce the negaction tendency. The resistance value of the doughnut $(r)$ is high because it is fresh and aromatic; it is very tempting. $R$ is equal to $r$ times $N$; that is, the force of resistance is higher for a fresh doughnut than for a stale one (higher r) and is higher when one is seriously dieting (higher N). As is illustrated in Figure 1, given enough time, the person will reach for the doughnut and begin to eat (at the point where the line representing BAR-T for eating crosses the line representing the BAR-T for writing).

When an activity has been initiated, the consummatory force (C) is applied. One will not continue eating doughnuts forever; at some point, one's hunger is satisfied and the tendency to eat decreases. The consummatory value (c) of eating doughnuts is greater than the $c$ value of eating celery; eating a doughnut satisfies and, therefore, decreases one's hunger at a faster rate than eating celery does. Also, the rate at which one is eating (BAR-T) determines the satisfaction of the hunger: $C=c * B A R-T$. 


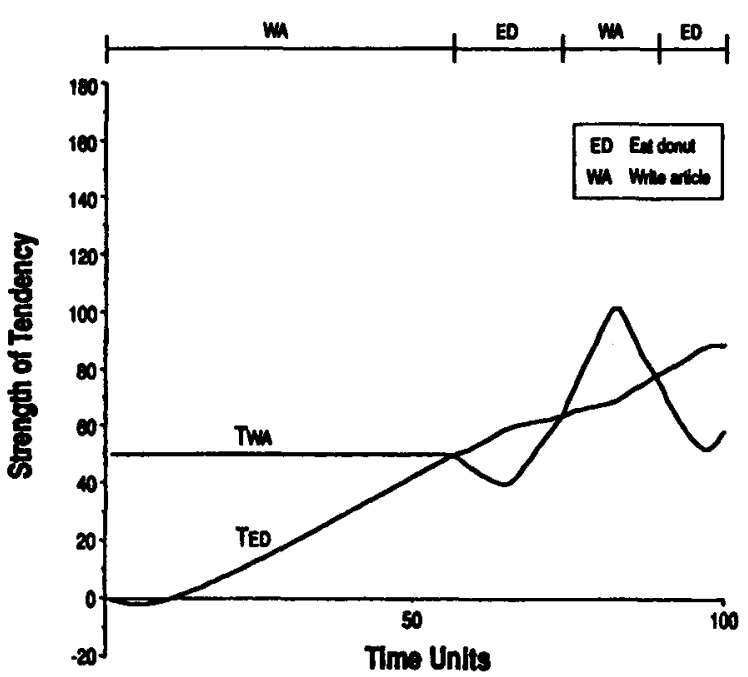

Figure 1. A FORTRAN simulation of two activities: writing an article and eating a doughnut. Changes in behavior occur when the top line representing the strength of tendency to write an article (TWA), for example, is crossed by the second line representing the strength of tendency to eat a doughnut (TED). The stream of behavior is projected to the top horizontal line.

The change in action tendency, $\Delta \mathrm{T}$, at each time unit equals $\mathrm{F}-\mathrm{C}$. The change in negaction, $\Delta \mathrm{N}$, at each time unit equals $\mathrm{I}-\mathrm{R}$.

A few more concepts must be explained before we can fully understand the computer simulation models. Selective attention refers to the person's concentration on the ongoing activity (looking at the computer screen), and the fact that the full $(100 \%)$ instigating and inhibitory forces of the doughnut are not applied. Selective attention can be set at any value greater than 0 and less than 1 . If the doughnut were on top of the computer, almost in the line of sight, selective attention would be high (perhaps .9). If it was almost out of sight, perpendicular to the line of sight, selective attention would be low (perhaps .2).

Displacement and substitution are concepts that refer to families of activities. The stimulus of the doughnut instigates eating the doughnut; through displacement, it also may instigate drinking a glass of milk if those have been associated in the past. For another person, eating doughnuts may be associated with drinking coffee, and drinking coffee is instigated through displacement. Substitution is shared consummatory force among related activities. Eating the doughnut will also satisfy the person's tendency to eat a sticky bun.

Finally, we have consummatory lags. It is assumed that the full force of consummation (satisfaction) does not occur immediately. It takes some amount of time for the person's blood sugar to rise. This is the initiation lag, the number of time units between starting to eat the doughnut and application of the full consummatory force. The cessation lag refers to the fact that the person will continue to experience a decrease in hunger (decrease in action tendency) after finishing the doughnut. Both the initiation lag and the cessation lag serve to separate the two action tendencies, the one just coming on and the one just going off, and avoid quick reversals of the two activities, a condition referred to as behavioral chatter.

\section{USES OF THE COMPUTER SIMULATION IN RESEARCH}

\section{Studies of Measurement Issues}

The FORTRAN IV version of the dynamics of action theory has been used in a number of studies to generate and explore research hypotheses. The first uses of the simulation were to simulate the measurement of the stream of behavior (Birch, 1972), to model risk-taking behavior (Reynolds, 1974), and to explore the effect of thoughts on action (Birch, J. W. Atkinson, \& Bongort, 1974). To challenge the applicability of classical reliability theory assumptions (i.e., internal consistency) to the thematic apperceptive test (TAT) measure of achievement motivation, J. W. Atkinson, Bongort, and Price (1977) ran a series of simulations depicting the time spent thinking about achievement themes in response to cues (TAT pictures) of varying strengths. Their results indicated that simulated individuals could be correctly identified as high or low in motivation even though the simulated test results were low in internal consistency.

Reuman, J. W. Atkinson, and Gallop (1986) simulated the behavior of 90 individuals by assuming three motives (achievement, affiliation, and other) and one ability (arithmetic). Using these personality parameters, they simulated nine behaviors, such as latency to perform an achievement task and time spent affiliating, to address two compelling issues in psychology: the consistency of behavior (Mischel, 1968) and the adequacy of factor analysis as a method for discovering the underlying personality structure of behavioral data. Reuman (1982) used dynamics of action simulations to model empirical results, showing that subjects who are high in behavioral variability (who change more often in a constant environment) write TAT stories that are high in construct validity, even though the stories are low in internal consistency.

\section{Studies of Achievement Behavior}

J. W. Atkinson and Birch (1974) applied the dynamics of action theory to achievement behavior by coordinating the concepts of instigating force and inhibitory force to tendencies to succeed and to avoid failure, respectively. The instigating force was equated to the tendency to achieve success, which is defined as the product of the motive to succeed times the incentive value of success times the subjective probability of success (J. W. Atkinson, 1957). The inhibitory force was equated to the tendency to avoid failure, which is defined as the product of the motive to avoid failure times the incentive value of failure times the subjective probability of failing. This changed the static model of achievement motivation to a dynamic model in which the instantaneous resultant tendency to achieve was the result of the interaction of the instigation and inhibitory forces in the situation. Kuhl and Blankenship (1979a, 1979b) investigated the effects of individual dif- 

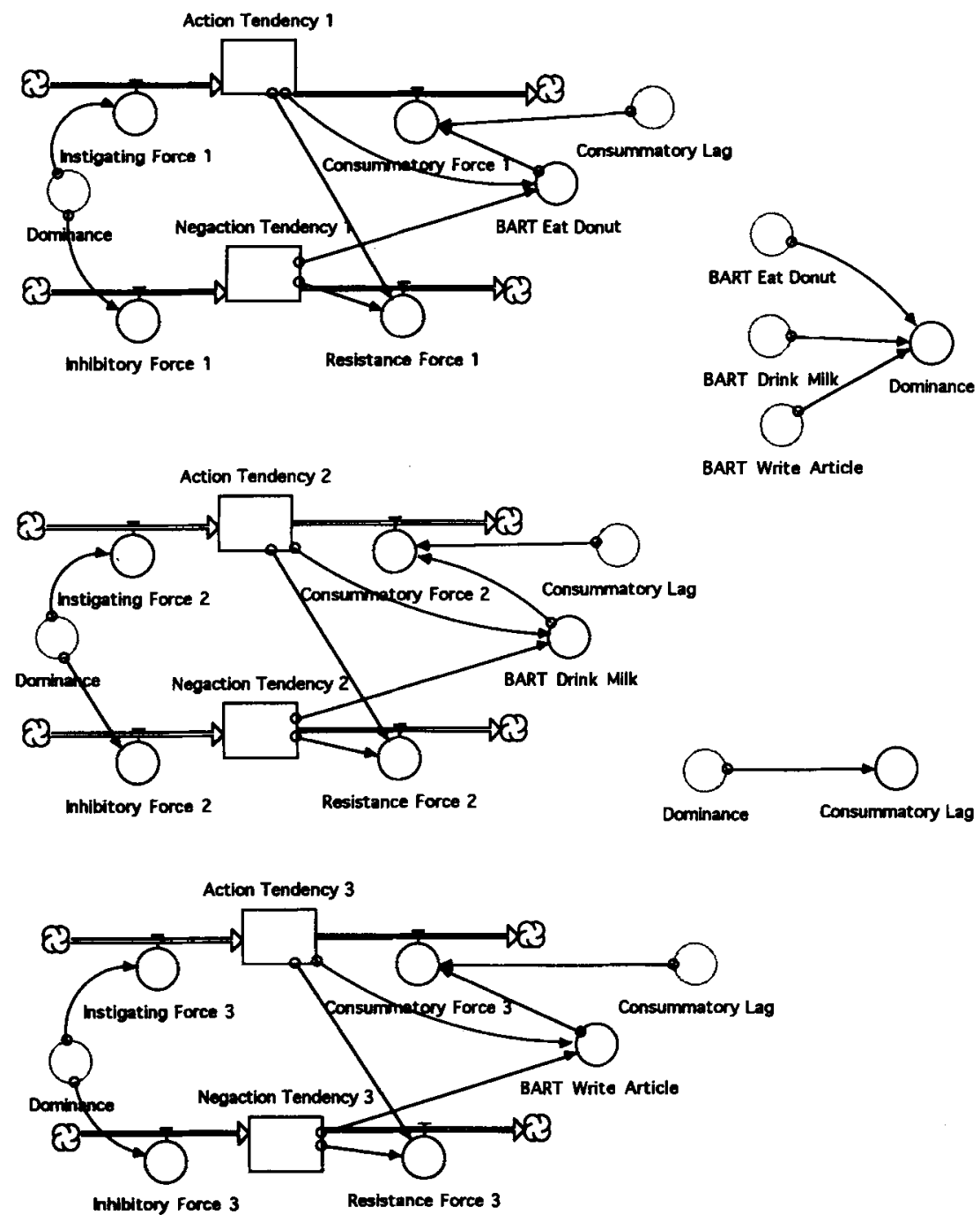

Figure 2. A STELLA-II icon-based program of the dynamics of action showing three activities: eating a doughnut (Action Tendency 1), drinking milk (Action Tendency 2), and writing an article (Action Tendency 3). A displacement relationship exists between eating a doughnut and drinking milk; it is programmed into the instigating forces 1 and 2 . The four converters to the right of the model contain the three ghosts of the BARTs, which determine Dominance. The dominance state $(1,2$, or 3$)$ is fed back to the three activities on the left by ghosts of Dominance. The ghost of Dominance also determines Consummatory Lag (illustrated at lower right).

ferences in achievement motivation, focusing on changes in risk preference through time. Empirical results supported the dynamics of action predictions that subjects with low achievement motivation would eventually move (over successive trials) to more difficult tasks, but that their movement would be slower than that of subjects with high achievement motivation. Houtmans (1989) and Slade and Rush (1991) have also examined this phenomenon.

The application of achievement motivation to the dynamics of action also "uncoupled" the effects of the motive to achieve success and the motive to avoid failure and led to the prediction that people with high fear of failure, if faced with an achievement task, would eventually engage in the achievement activity. However, it should take them much longer than people with low fear of failure, since they would have to overcome the effects of resistance. Blankenship (1987) reported empirical support for that assumption. Subjects with high fear of failure took longer to go to an achievement task following an anxiety-producing manipulation (the apparent breakdown of a computer) than subjects with low fear of failure.

The consummatory value of achieving has been equated by J. W. Atkinson and Birch $(1974,1978)$ to success and failure outcomes. Revelle and Michaels (1976) used that relationship to explain changes in risk preference through time. Kuhl and Blankenship (1979a, 1979b) elaborated on that interpretation, and Blankenship (1982) explored the relative consummatory value of success and failure, concluding that the consummatory value of success at an easy task is greater than the consummatory value of suc- 

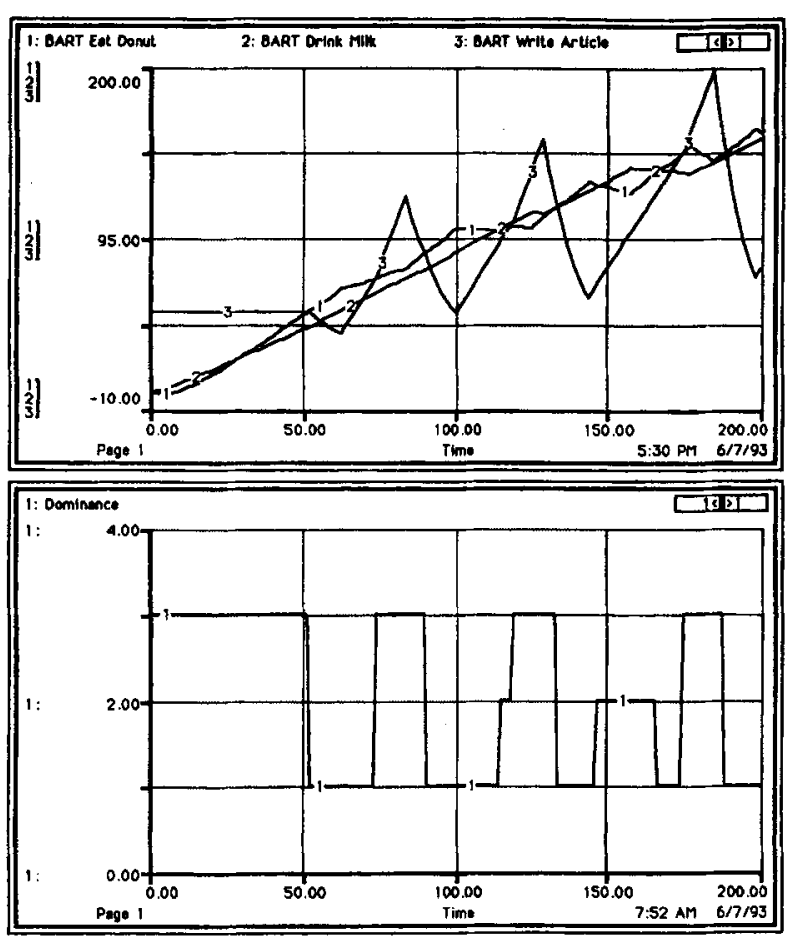

Figure 3. STELLA-II simulations of three activities: eating a doughnut, drinking milk, and writing an article. In the top graph, the strength of tendency for each of the three activities is plotted as a function of time, and the activity represented by the top line is dominant. The bottom graph is a plot of dominance state over time. When dominance state equals 3 , writing an article is the dominant activity. When dominance equals 1, eating a doughnut is dominant. Dominance state 2 represents drinking milk.

cess at a difficult task. Blankenship (1986) also explored the effects of substitution on changes in risk preference.

Blankenship (1992) used the dynamics of action to generate hypotheses about persistence at achievement tasks of varying difficulty levels. Although dynamics of action simulations could not model all of the experimental results, the theory did receive support from differential persistence of subjects with low resultant achievement motivation; they persisted longer at the easy task than at the difficult task, whereas subjects with high achievement motivation spent more time at the difficult task than at the easy task. This finding can be explained by the dynamics of action model, but it is contrary to predictions from Atkinson's earlier risk-taking model (J. W. Atkinson, 1957).

\section{STELLA-I, A TEACHING SIMULATION}

We denote the STELLA-II simulation a teaching tool because of its icon-oriented model-building capabilities, which facilitate the visualizing of the model. The acronym STELLA stands for Systems Thinking, Experiential Learning Laboratory, with Animation (High Performance Systems, Inc., 1990). It is currently available for the Macintosh computer and for DOS with Windows. It has icons that can be clicked and placed on a palette in a format similar to MacDraw and MacPaint.

Because of its user-friendly interface, STELLA is being used by a wide range of students in a wide variety of content areas. For example, it has been used in grade schools and high schools to teach students systems thinking, the ability "to understand the behavior of complex phenomena over time" (Mandinach \& Cline, 1992). Hopkins (1992) used STELLA to teach Hamlet to high school students, modeling the changes in motivation experienced by Hamlet as he learned about his Uncle Claudius' actions. In describing the enthusiasm of her students, Hopkins noted that "The use of precise numbers to talk about psychological motives and human responses had given them power, had given them a system to communicate with" (p. 94). Niedderer, Schecker, and Bethge (1991) used STELLA to teach physics and found that it helped high school students increase "qualitative conceptual reasoning" when they created iconic models of laboratory problems (p. 92). In a university honors class, computer simulation of the Rescorla-Wagner model of learning, done with STELLA-II, allowed students to critique explanations of complex phenomena, such as transswitching (Blankenship, Schorie, Shaw, \& Tumlinson, 1994).

In this simulation of the dynamics of action, the elements of STELLA that will be used are reservoirs, inflows (and outflows), and converters. The action tendency and the negaction tendency will be represented as reservoirs (rectangles) that are fed by the instigating force (an inflow) and the inhibitory force (an inflow), respectively. STELLA is designed for time series modeling, and has built-in finite difference equations. At each change in time (dt) the set amount of instigating force flows into the action tendency reservoir. Correspondingly, inhibitory force flows into the negaction tendency reservoir.

The outflows for the action tendency and the negaction tendency are the consummatory force and the force of resistance, respectively. Whereas the force of resistance decreases the negaction tendency at each dt, the consummatory force decreases the action tendency only if the activity is ongoing. In the simplest case, an activity is ongoing when it is dominant (has the highest resultant tendency of all activities).

BAR-T, the resultant action tendency, is represented by a converter (a circle) that is connected to the action tendency reservoir and to the negaction reservoir. By clicking behind the converter, the programmer is able to define BART_Eat_Donut (for example) as [Action Tendency_1 - Negaction_Tendency_1]. In the case with three activities (see Figure 2), dominance is determined through the comparison of values for BART for Eat Doughnut, Drink Milk, and Write Article. One of the features of STELLA, which allows for less cluttered diagrams, is the creation of ghosts to duplicate parameters. Dominance is determined by the logical sequence:

[If (BART_Eat_Donut $>=$ BART_Drink_Milk) and (BART_Eat_Donut $>=$ BART_Write_Article) then 1 

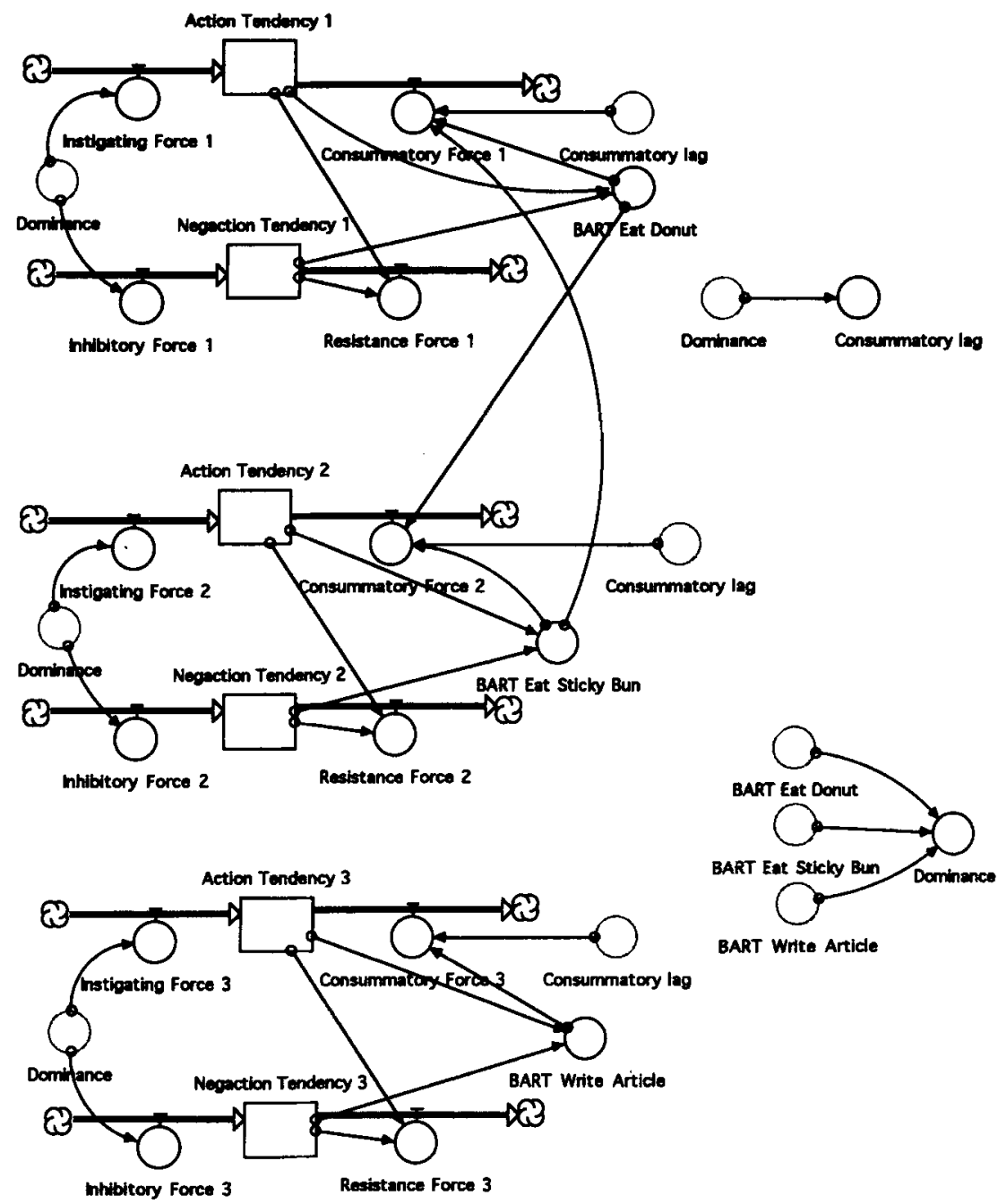

BART Write Article

Figure 4. A STELLA-II program showing three activities: eating a doughnut, eating a sticky bun, and writing an article. A substitution relationship exists between eating a doughnut and eating a sticky bun; it is programmed into the consummatory forces 1 and 2. As in Figure 2, ghosts of the BARTs determine Dominance, which is fed back to the three activities as ghosts. The ghost of Dominance also determines Consummatory_Lag.

else if (BART_Drink_Milk>=BART_Eat_Donut) and (BART_Drink_Milk $>=$ BART_Write_Article) then 2

else 3].

In this portion of the diagram, the BARTs are represented by ghosts (the converter circles are lighter). Subsequently, the value for Dominance is transferred back to the three activity diagrams as a ghost. In programming with ghosts, anything that is changed on the "living" counterpart (e.g., the original Dominance converter) is automatically changed on its ghost.

\section{Displacement and Selective Attention}

Because the doughnut is associated with drinking milk in the past, Instigating_Force_1 for eating the doughnut also displaces or adds to the Instigating_Force_2 for drinking milk. This, and the concept of selective attention, the idea that the full Instigating_Force_1 will only be applied if the activity is dominant, are programmed for Instigating_Force_2 with the following algorithm:

[If Dominance $=2$ then $1.0+(0.6 * 0.2 * 2.0)$

else if Dominance $=1$ then $(0.6 * 1.0)+(0.2 * 2.0)$

else $(0.6 * 1.0)+(0.6 * 0.2 * 2.0)]$

To interpret this logical sequence, bear in mind that the instigating force for activity 2 (drink milk) is 1.0 and the instigating force for activity 1 (eat doughnut) is 2.0 . The selective attention is set at 0.6 , and the displacement relationship is set at 0.2 . If Dominance $=2$ (drinking milk is dominant) the activity gets its full instigating force (1.0) plus 0.2 displacement from the instigating force for activity $1(2.0)$, which is not dominant and therefore is re- 

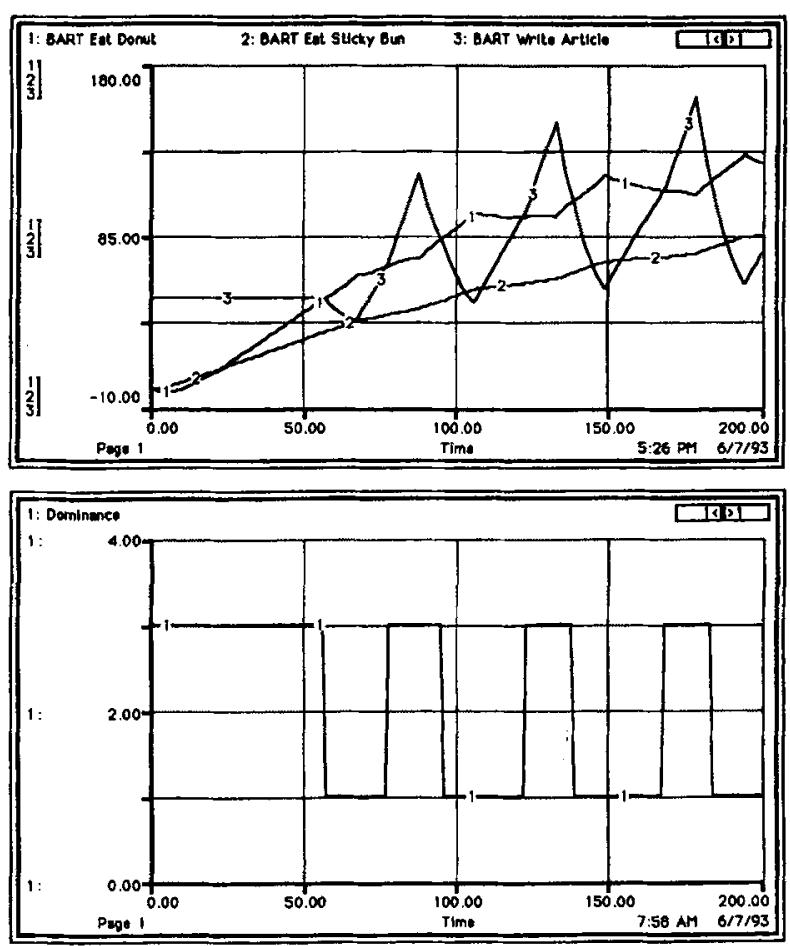

Figure 5. STELLA-II simulations of three activities: eating a doughnut, eating a sticky bun, and writing an article. In the top graph, strength of tendency is plotted over time. In the bottom graph, dominance state is plotted. When dominance equals 3 , writing an article is dominant and ongoing. When dominance equals 1, eating a doughnut is dominant. If dominance were equal to 2, eating a sticky bun would be dominant; however, substitution keeps the eating of a sticky bun from becoming dominant.

ceiving only 0.6 selective attention. If Dominance $=1$ (eating doughnut is dominant) drinking milk gets 0.6 of its instigating force (because of selective attention) plus 0.2 displacement from the full instigating force for activity $1(2.0)$. If, however, Dominance $=3$ (writing article is dominant), the instigation from both activity 1 and activity 2 is 0.6 of the full force (selective attention) and the displacement from activity 1 is 0.2 times 2.0 . As is shown in Figure 3, our simulated person takes a sip of milk at time unit 115 and a longer drink at time unit 147. Selective attention is also applied to the inhibitory force. If the activity is dominant, it gets its full inhibitory force; if not, it gets a fraction (in this case 0.6).

\section{Consummatory Lags}

Consummatory force is also contingent on the dominance status of the activity, but delayed by a number of time units. Thus, a connector from the ghost of Dominance to the Consummatory_Lag converter defines the Consummatory_Lag as [DELAY(Dominance,10)]. The DELAY function in STELLA is one of many built-in functions with preset arguments. In this case, the value of Dominance is taken from 10 time units before the current time unit. (In other words, the current value of Dominance is delayed 10 time units.) This serves the purposes of both the initiation consummatory lag and the cessation consummatory lag. The full consummatory force is not applied until after the activity has been dominant 10 time units, and the consummatory force does not go off until 10 time units after the activity goes out of dominance. For example, Consummatory_Force_1, which has a consummatory value(c) of 0.02 , is defined as

$$
\begin{aligned}
& \text { [If Consummatory_Lag=1 } \\
& \text { then }(0.02 * \text { BART_Eat_Donut) } \\
& \text { else } 0 \text { ]. }
\end{aligned}
$$

The force of resistance is determined in a slightly different way from the consummatory force. As mentioned previously, the Resistance_Force_1 is decreasing the $\mathrm{Ne}$ gaction_Tendency_1 at all times, not just when the activity is dominant. Further, it is determined by the following function:

$$
\begin{gathered}
\text { [0.1*Min(Action_Tendency_1, } \\
\text { Negaction_Tendency_1) }] .
\end{gathered}
$$

The resistance value (r), equal to 0.1 , is multiplied by whichever is smaller, the action tendency or the negaction tendency (see J. W. Atkinson \& Birch, 1970, p. 239).

\section{Substitution}

Two activities that are associated with each other can also have a substitution relationship. Whereas displacement is indirect instigating force, substitution is indirect consummatory force. Take the example of the sticky bun, which is sitting on a nearby table. (See Figures 4 and 5.) When the doughnut is being eaten, the consummatory force that is decreasing the tendency to eat the doughnut is also indirectly decreasing the tendency to eat the sticky bun. Substitution from activity 1 to activity 2 is formulated as follows:

$$
\begin{aligned}
& \text { [If Consummatory_Lag=2 } \\
& \text { then }(0.01 * \text { BART_Eat_Sticky_Bun }) \\
& \text { else if Consummatory_Lag=1 } \\
& \text { then }(0.2 * 0.02 * \text { BART_Eat_Donut }) \\
& \text { else } 0 \text { ]. }
\end{aligned}
$$

In other words, if activity 2 (Eat Sticky Bun) is dominant, the consummatory value $(c=0.01)$ is applied to BART_Eat_Sticky_Bun. If, as is the case in this simulation, activity 1 is dominant, the consummatory force that is substituted from activity 1 is 0.2 (the substitution value) times 0.02 (the consummatory value, $c$, of eating the doughnut) times BART_Eat_Donut. If writing is the dominant activity, no consummatory force (direct or indirect) is applied to activity 2 . In this simulation, because the consummatory force from eating the doughnut is applied indirectly to eating the sticky bun during a substantial portion of the time, eating the sticky bun never becomes the dominant activity. (There is no displacement relationship between eating the doughnut and eating the sticky bun in this simulation.) 


\section{CONCLUSIONS}

We believe that the STELLA-II simulation of the dynamics of action theory will facilitate the teaching of the model in undergraduate and graduate motivation and personality classes. Several textbooks currently include the model (Hoyenga \& Hoyenga, 1984; Klein, 1982; Reeve, 1992; Weiner, 1985), and the coverage would be more complete if the STELLA-II simulations were presented as a class demonstration or as a part of a laboratory exercise for all students. Giving students experience in choosing parameter values to model the amount of time spent at achievement tasks of varying difficulty level, for example, would give students practice in conceptual thought.

\section{REFERENCES}

ATKINSON, D. J. (1986). Microcomputer simulation of the dynamics of action: Programs in BASIC. In J. Kuhl \& J. W. Atkinson (Eds.), Motivation, thought, and action (pp. 337-354). New York: Praeger.

Atkinson, J. W. (1957). Motivational determinants of risk-taking behavior. Psychological Review, 64, 359-372.

ATKINSON, J. W., \& BIRCH, D. (1970). The dynamics of action. New York: Wiley.

ATKInson, J. W., \& BIRCH, D. (1974). The dynamics of achievementoriented activity. In J. W. Atkinson \& J. O. Raynor (Eds.), Motivation and achievement (pp. 271-325). Washington, DC: V. H. Winston.

Atkinson, J. W., \& BIRCH, D. (1978). An introduction to motivation (2nd ed.). New York: Van Nostrand Reinhold.

Atkinson, J. W., Bongort, K., \& Price, L. H. (1977). Explorations using computer simulation to comprehend thematic apperceptive measurement of motivation. Motivation \& Emotion, 1, 1-27.

BIRCH, D. (1972). Measuring the stream of activity. In Michigan mathematical program MMPP72-2 (pp. 1-24). Ann Arbor: University of Michigan Press.

Birch, D., Atrinson, J. W., \& Bongort, K. (1974). Cognitive control of action. In B. Weiner (Ed.), Cognitive views of human motivation (pp. 71-84). New York: Academic Press.

BLANKENSHIP, V. (1982). The relationship between consummatory value of success and achievement task difficulty. Journal of Personality \& Social Psychology, 42, 911-924.

BlankeNSHIP, V. (1986). Uses of the computer in motivational psychology. In D. R. Brown \& J. Veroff(Eds.), Frontiers of motivational psychology (pp. 87-106). Berlin: Springer-Verlag.

BLANKENSHIP, V. (1987). A computer-based measure of resultant achievement motivation. Joumal of Personality \& Social Psychology, 53, 361-372.

BLANKENSHIP, V. (1992). Individual differences in resultant achievement motivation and latency to and persistence at an achievement task. Motivation \& Emotion, 16, 35-63.

Blankenship, V., Schorie, S. S., ShaW, A. J., \& Tumlinson, J. (1994). Teaching the Rescorla-Wagner model using STELLA-II. Behavior Research Methods, Instruments, \& Computers, 26, 128-133.
BONGORT, K. (1975). Most recent revision of computer program for dynamics of action [computer program]. Ann Arbor: University of Michigan.

High Performance Systems, Inc. (1990). STELla-II user's guide [Computer software manual]. Hanover, $\mathrm{NH}$ : Author.

HoPKINS, P. L. (1992). Simulating Hamlet in the classroom. System Dynamics Review, 8, 91-98.

Houtmans, M. J. M. (1989). The influence of external rewards and performance feedback on dynamic aspects of task motivation. Nijmegen: Instituut voor Orthopedogogiek.

HoYenga, K. B., \& HoyenGA, K. T. (1984). Motivational explanations of behavior: Evolutionary, physiological, and cognitive ideas. Monterey, CA: Brooks/Cole.

KLEIN, S. B. (1982). Motivation: Biosocial approaches. New York: McGraw-Hill.

KuHL, J., \& BlaNKENSHIP, V. (1979a). Behavioral change in a constant environment: Shift to more difficult tasks with constant probability of success. Journal of Personality \& Social Psychology, 37, $551-563$.

KUHL, J., \& BLANKENSHIP, V. (1979b). The dynamic theory of achievement motivation: From episodic to dynamic thinking. Psychological Review, 86, 141-151.

Mandinach, E. B., \& Cline, H. F. (1992). Systems, science, and schools. System Dynamics Review, 9, 195-206.

Mischel, W. (1968). Personality and assessment. New York: Wiley.

Niedderer, H., Schecker, H., \& BethGe, T. (1991). The role of computer-aided modelling in learning physics. Journal of Computer Assisted Learning, 7, 84-95.

ReEve, J. M. (1992). Understanding motivation and emotion. Fort Worth, TX: Holt, Rinehart \& Winston.

ReUman, D. (1982). Ipsative behavioral variability and the quality of thematic apperceptive measurement of the achievement motive. Journal of Personality \& Social Psychology, 43, 1098-1110.

Reuman, D., Atkinson, J. W., \& Gallop, G. (1986). Computer simulation of behavioral expressions of four personality traits. In J. Kuhl $\&$ J. W. Atkinson (Eds.), Motivation, thought, and action (pp. 203234). New York: Praeger.

Revelle, W., \& Michaels, E. J. (1976). The theory of achievement motivation revisited: The implications of inertial tendencies. Psychological Review, 83, 394-404.

REYNOLDS, M. K. (1974). Computer simulation of effects of individual differences in achievement motivation on risk preference under free operant conditions. In J. W. Atkinson \& J. O. Raynor (Eds.), Motivation and achievement (p. 324). Washington, DC: V. H. Winston.

SEltzer, R. A. (1973). Simulation of the dynamics of action. Psychological Reports, 32, 859-872.

SEltZER, R. A., \& SAWUSCH, J. R. (1974). Computer program written to simulate the dynamics of action. In J. W. Atkinson \& J. O. Raynor (Eds.), Motivation and achievement (pp. 411-423). Washington, DC: V. H. Winston.

SLADE, L. A., \& RUSH, M. C. (1991). Achievement motivation and the dynamics of task difficulty choices. Journal of Personality \& Social Psychology, 60, 165-172.

WEINER, B. (1985). Human motivation. New York: Springer-Verlag.

(Manuscript received November 14, 1994; revision accepted for publication January 24, 1995.) 